\title{
Alternative splicing and cell survival: from tissue homeostasis to disease
}

\author{
Maria Paola Paronetto*,1,2 Ilaria Passacantilli ${ }^{2,3}$ and Claudio Sette ${ }^{\star 2,3}$
}

Most human genes encode multiple mRNA variants and protein products through alternative splicing of exons and introns during pre-mRNA processing. In this way, alternative splicing amplifies enormously the coding potential of the human genome and represents a powerful evolutionary resource. Nonetheless, the plasticity of its regulation is prone to errors and defective splicing underlies a large number of inherited and sporadic diseases, including cancer. One key cellular process affected by alternative splicing is the programmed cell death or apoptosis. Many apoptotic genes encode for splice variants having opposite roles in cell survival. This regulation modulates cell and tissue homeostasis and is implicated in both developmental and pathological processes. Furthermore, recent evidence has also unveiled splicing-mediated regulation of genes involved in autophagy, another essential process for tissue homeostasis. In this review, we highlight some of the best-known examples of alternative splicing events involved in cell survival. Emphasis is given to the role of this regulation in human cancer and in the response to chemotherapy, providing examples of how alternative splicing of apoptotic genes can be exploited therapeutically.

Cell Death and Differentiation (2016) 23, 1919-1929; doi:10.1038/cdd.2016.91; published online 30 September 2016

\section{Facts}

- The complexity of the apoptotic program is achieved through a broad spectrum of proteins acting at transcriptional, post-transcriptional and post-translational levels.

- Through alternative processing of their precursor mRNAs (pre-mRNAs), many apoptotic genes encode for multiple protein variants displaying opposite functions.

- Dysregulation of apoptotic splice variants contributes to the pathogenesis of human diseases.

- Modulation of splicing by small molecules is emerging as a valuable therapeutic approach to human diseases.

\section{Open Questions}

- What are the specific splicing factors that contribute to key alternative splicing events in apoptotic genes of relevance for normal development or human diseases?

- Is alternative splicing of apoptotic genes targetable for therapeutics purpose?

- What is the contribution of alternative splicing to the regulation of autophagy?

The balance between cell proliferation and death insures dynamic tissue remodeling during development and maintains tissue homeostasis in adult organisms. When necessary, cells must respond to negative environmental cues and/or endogenous signals by activating a 'cell death' program named apoptosis. If these rules normally in act in tissues are ignored, pathological conditions can arise. ${ }^{1-3}$

The ability to surgically remove erroneous and potentially deleterious cells is an indispensable requirement for the physiology of tissues. ${ }^{1}$ Through apoptosis, damaged cells trigger their own destruction with little effect on the surrounding tissue. ${ }^{1-4}$ Apoptosis occurs via two interlinked pathways: the extrinsic pathway, typically activated by pro-apoptotic receptors at the cell surface; the intrinsic pathway, triggered by mitochondrial signals within the cell (Figure 1). These two pathways converge at the level of common effectors, which orchestrate and execute the apoptotic program. ${ }^{4}$

An example of how apoptosis participates in development and tissue homeostasis is provided by the nervous system. Extensive elimination of neurons through apoptosis is an essential step for the functional and structural maturation of the brain. ${ }^{5}$ Viability of neurons during embryogenesis depends on trophic factors, such as nerve growth factor, ${ }^{6}$ secreted by neighboring cells and competition for these cues results in survival of some neurons and death of others. ${ }^{7}$ Another example of developmentally programmed cell death program is follicular atresia in ovary. Factors secreted by granulosa cells, such as estradiol and insulin-like growth factor, are essential for

\footnotetext{
'Department of Movement, Human and Health Sciences, University of Rome 'Foro Italico', Rome 00135, Italy; ${ }^{2}$ Laboratories of Cellular and Molecular Neurobiology and of Neuroembryology, Fondazione Santa Lucia, Rome 00143, Italy and ${ }^{3}$ Department of Biomedicine and Prevention, University of Rome 'Tor Vergata', Rome, Italy ${ }^{*}$ Corresponding author: MP Paronetto or C Sette, Department of Biomedicine and Prevention, University of Rome Tor Vergata, Via Montpellier 1, Rome 00143, Italy. Tel: +3906 72596260 or +3906 501703218; Fax: +3906 72596268. E-mail: mariapaola.paronetto@ uniroma4.it or claudio.sette@uniroma2.it

Abbreviations: AS, alternative splicing; snRNP, small nuclear ribonucleoprotein; hnRNP, heterogeneous nuclear ribonucleoprotein; SRSF, serine arginine-rich splicing factor; Pre-mRNA, precursor messenger RNA; PTC, premature termination codon; NMD, nonsense-mediated decay; LncRNA, long non-coding RNA; UTR, untranslated regions; BH, BCL-2 family-homology; ASO, antisense oligonucleotide; PCa, prostate cancer; PDAC, pancreatic ductal adenocarcinoma; AML, acute myeloid leukemia; SMA, spinal muscular atrophy

Received 05.2.16; revised 26.5.16; accepted 15.7.16; Edited by J Bartek; published online 30 September 2016
} 


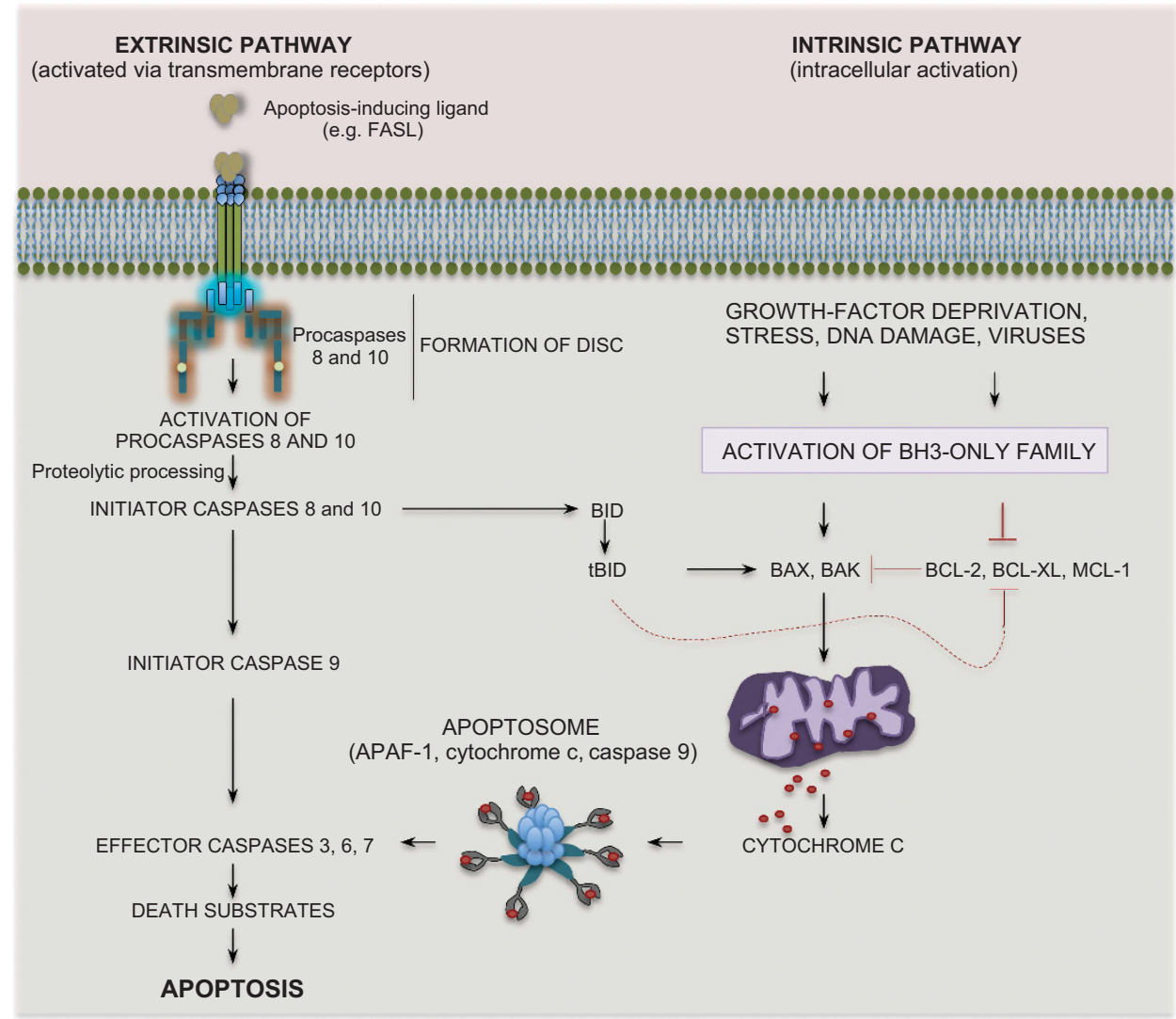

Figure 1 The apoptotic pathways. Schematic representation of the the extrinsic (death receptor) pathway (left) and of the intrinsic (mitochondrial) pathway of apoptosis (right). Binding of ligands of the TNF family leads to oligomerization of death receptors and subsequent recruitment and activation of initiator caspases (caspase-8 and -10) via adaptor proteins. The initiator caspases target effector caspases for proteolytic cleavage and activation. In response to an apoptotic stimulus pro-apoptotic BCL-2 proteins lead to permeabilization of the outer mitochondrial membrane and release of cytochrome $c$, which then binds APAF-1. Next, a conformational change leads to recruitment of an initiator caspase (caspase-9) and formation of the apoptosome. Caspase-9 in turn activates effector caspases (for example, caspase-3). In both pathways the activated caspases cleave selected nuclear and cytoplasmic target proteins for the accomplishment of the apoptotic program

follicle growth and deprivation of them or stimulation of death receptors, is the main cause of follicle regression before birth. ${ }^{8}$

To avoid adverse effects, apoptotic pathways are precisely regulated at multiple levels and interconnected with checkpoints monitoring the crucial events in the cell life. Regulation is achieved through a broad spectrum of proteins that act at multiple layers. ${ }^{1-4}$ Notably, many apoptotic genes encode for protein variants with opposite functions through alternative splicing (AS) of the precursor mRNA (pre-mRNA), ${ }^{9}$ suggesting that this step in the regulation of gene expression is particularly suited for the fine-tuned control required to properly execute apoptosis.

\section{Alternative Splicing and Apoptosis}

Eukaryotic genes are characterized by short exons interspersed between long non-coding introns. Splicing of introns is catalyzed by the spliceosome, a macromolecular machinery composed of five small nuclear ribonucleoprotein particles (U1, U2, U4, U5 and U6 snRNP) and many auxiliary proteins. ${ }^{10}$ When the splice sites display high levels of sequence conservation, exons are almost always included in the mRNA (constitutive exons). Nevertheless, many exons lack strong exon-intron consensus sequences and are subjected to regulation (alternative exons). In this case, their recognition is tuned by splicing factors that recognize enhancer and silencer sequences in the pre-mRNA. ${ }^{11}$ It is the interplay between antagonistic splicing factors to determine whether a target exon is included or skipped from the mature mRNA. This flexibility in splicing regulation allows alternative assortment of exons in the transcripts encoded by virtually every multi-exon gene, thus greatly expanding the coding potential and plasticity of genomes. ${ }^{12}$

Regulation of apoptosis is a typical example of the impact of AS in the modulation of biological processes. Several apoptotic genes encode splice variants having opposite roles. ${ }^{9}$ For example, the long isoforms of $B C L-X(B C L-X)$ and APAF1 $\left(\mathrm{APAF}_{\mathrm{L}}\right.$ ) protect cells against apoptosis, whereas their short isoforms $\left(B C L-X_{S}\right.$ and $\left.A P A F 1_{S}\right)$ promote it. ${ }^{13,14}$ Conversely, the long isoform of CASP2 (ICH-1L) induces apoptosis, whereas the short isoform (ICH-1S) inhibits it. ${ }^{15}$

Dysregulation of apoptotic splice variants expression contributes to human diseases, as cancer and neurodegenerative disorders. ${ }^{1-3}$ For instance, use of alternative promoters and AS generates a complex pattern of pro- and anti-apoptotic isoforms of the tumor-suppressor TP73 gene. Transcription 
from the P1 promoter yields the full-length protein with proapoptotic activity. However, usage of the P2 promoter in intron 3 and/or AS of exons 2 and 3 produce variants that lack the $\mathrm{N}$-terminal trans-activation domain and counteract the tumorsuppressor activity of p53 and p73. ${ }^{16}$ Likewise, differential expression of TP53 splice variants can switch astrocyte function from neuroprotective $(\Delta 133 p 53)$ to neurodegerative (p53 $\beta)$. An altered ratio of these variants in favor of the neurotoxic p53 $\beta$ isoform was detected in brain of patients affected by Alzheimer's disease and amyotrophic lateral sclerosis, ${ }^{17}$ thus linking TP53 AS to common forms of neurodegenerative diseases.

Herein, we will illustrate molecular mechanisms involved in AS regulation of three well-studied apoptotic genes (FAS, CASP9 and BCL2L1) encoding antagonistic variants. Moreover, we will describe the impact of apoptotic genes splicing in cancer progression and chemoresistance, providing examples of how AS modulation can be envisioned as therapeutic tool for human cancer.

\section{Alternative Splicing Regulation: Lessons from Apoptotic Genes}

Although most genes undergo AS and many biological processes are likely affected by it, ${ }^{12}$ in few cases the specific impact of AS on gene functions is well illustrated as for apoptosis. For this reason, genes like those encoding the membrane-bound death receptor FAS, the apoptotic modulator BCL-X and the protease caspase 9 have been employed as model systems to investigate the basic rules of AS regulation (Figure 2).

FAS. FAS (CD95/APO-1/TNFRSF6) belongs to the tumor necrosis factor receptor family. ${ }^{18}$ Binding of FAS to its ligand FASL (CD95L/CD178/TNFSF6) triggers apoptosis. ${ }^{18}$ FAS and FASL are involved in T-cell-mediated cytotoxicity and in feedback mechanisms dampening immune reactions. FASmediated apoptosis is implicated in the maintenance of immune cell homeostasis and in autoimmunity, ${ }^{18,19}$ indicating that a tight balance between FAS and FASL insures a proper immune response.

In addition to FAS full-length mRNA, shorter transcripts exist (Figure 2a). In most variants, AS alters the open reading frame and introduces premature termination codons (PTCs), resulting in transcripts that are candidates for nonsense-mediated decay (NMD) and likely not translated into proteins. However, in-frame skipping of exon 6 yields a soluble protein that lacks the transmembrane domain and inhibits FASL-mediated apoptosis $^{20}$ (Figure 2a). Because of its functional relevance, this event has been intensively studied. Binding of the T-cell intracellular antigen (TIA)-1 to intron $6,{ }^{21}$ or of the Ewing Sarcoma protein (EWS) within the exon, ${ }^{22}$ favors splicing of the full-length variant. Both splicing factors interact with U1C and promote U1 snRNP assembly, ${ }^{21-25}$ possibly facilitating recognition of the 5 '-splice site by the spliceosome (Figure $2 \mathrm{~d}$ ). This regulation is modulated by the FAS-activated serine/ threonine kinase (FAST K), which phosphorylates TIA-1 and enhances U1 snRNP recruitment. ${ }^{26}$ Thus, FAS signaling can modulate splicing of its own transcript, suggesting that this mechanism forms an autoregulatory loop amplifying FAS response at occurrence, as during sustained T-cell activation. Conversely, the polypyrimidine tract-binding protein 1 $(\mathrm{PTBP} 1)^{25}$ and the $\mathrm{Hu}$ antigen $\mathrm{R}$ protein $(\mathrm{HuR})^{27}$ bind to an exonic splicing silencer and inhibit association of the U2 snRNP auxiliary factor (U2AF) and U2 snRNP with the $3^{\prime}$ splice site, thus impairing exon 6 inclusion (Figure 2d). A different mechanism was described for the tumor-suppressor RBM5/Luca-15/H37. RBM5 directly contacts components of the U4/5/6 tri-snRNP and inhibits catalytic activation of the spliceosome after exon 6 definition by the U1 and U2 snRNPs. ${ }^{28}$ The long non-coding RNA (IncRNA) FAS-AS1, corresponding to an antisense transcript of $F A S$, sequesters RBM5 and interferes with skipping. ${ }^{29}$ It is likely that competition between all these splicing regulators determines the outcome of FAS splicing in any given cell, predisposing it to survive or die to different cues. In this regard, genome-wide screening for regulators of exon 6 splicing identified several cellular pathways involved in its modulation, ${ }^{30}$ highlighting its multifactorial nature in human cells.

Splicing factors recruitment to FAS pre-mRNA could offer therapeutic perspectives in diseases associated with FAS function, like cancers displaying poor clinical outcomes (that is, Hodgkin's lymphomas, autoimmune lymphoproliferative syndromes). For instance, forced expression of EWS increased FAS and enhanced FAS-induced death in Ewing Sarcoma cells. ${ }^{22}$ Thus, development of small molecules mimicking EWS function may result useful to directly impair cancer cell survival.

Caspase 9. Apoptosis culminates with the activation of caspases (Figure 1), a family of proteases that cleave substrates at the carboxyl side of specific aspartate residues. ${ }^{31}$ Caspases share similarities in sequence, structure, and substrate specificity. They are synthesized as single-chain procaspases (30-50 kDa), comprising an $\mathrm{NH} 2$-terminal domain, a large $(18-20 \mathrm{kDa})$ and a small subunit $(\sim 10 \mathrm{kDa})^{31,32}$ (Figure 2b). Activation involves proteolytic processing between domains and binding to cofactors. Procaspase- 9 activation is crucial for the accomplishment of the classic apoptotic program, and requires formation of a complex with APAF-1 and cytochrome c. ${ }^{31-33}$ Knockout of the caspase 9 gene (Casp9) in mice caused perinatal death, due to excess cell survival causing malformations during brain development. ${ }^{34}$ Moreover, Casp-9 knockout thymocytes, ES cells, and fibroblasts are resistant to apoptosis, ${ }^{34}$ confirming its key role in the execution of apoptosis.

The human CASP9 gene encodes at least three proteincoding splice variants generated by either inclusion/exclusion of the exon 3,4,5,6 cassette or by different assortment of first exons (Figure 2b). In the latter case, the variants contain different 5'-untranslated regions (UTR) and lack the canonical start codon, with translation initiating at downstream codons and yielding shorter $\mathrm{N}$-termini. On the other hand, skipping of exons 3,4,5,6 yields caspase-9 short (caspase-9S), which behaves as dominant-negative by counteracting death induced by the main isoform. ${ }^{35}$ Caspase-9S lacks the catalytic domain but retains the caspase APAF-1-association domain and the small subunit (Figure 2b). Hence, it competes with caspase- 9 for binding to APAF-1 and contributes to resistance to apoptosis. ${ }^{35}$ 
Binding of the splicing factor SRSF1 to a purine-rich ciselement in intron 6, $24 \mathrm{bp}$ downstream of the splice site, promotes inclusion of the exon 3,4,5,6 cassette. $^{36}$ Instead, heterogeneous nuclear ribonucleoprotein $L$ ( $h n R N P L$ ) recognizes a purine-rich exonic splicing silencer in exon $3 .^{37}$
Phosphorylation of hnRNP L modulates CASP9 AS. When $\mathrm{hnRNP} L$ is phosphorylated on Serine 52 , such as in non-small cell lung cancers (NSCLC), its splicing activity is induced, leading to skipping of the cassette. ${ }^{37}$ Candidate survival/ oncogenic kinases (i.e., GSK3 $\beta$, AKT, and casein kinase II) are a

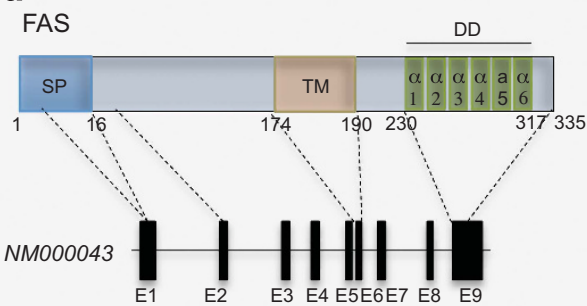

NM152871 (FAS $\triangle E x 6)$

NM152872 (FAS $\triangle E x 8)$

NR028034
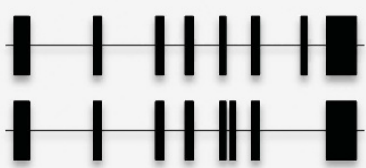

NR028035

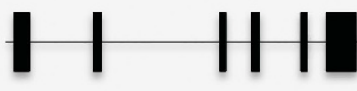

NR02803

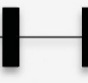

NR028036

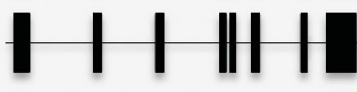

NR028033

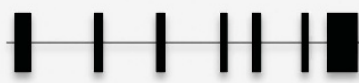

b CASPASE9

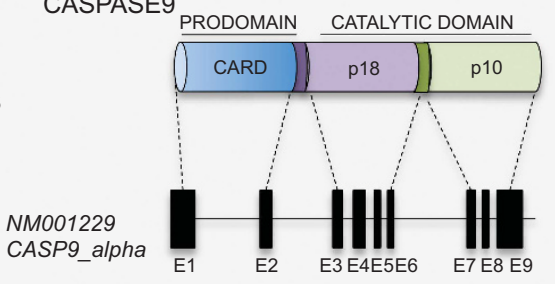

NM032996

NM_001278054

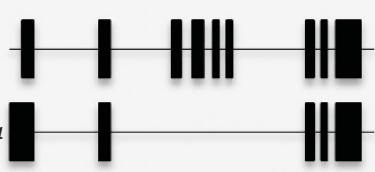

C

BCL-X

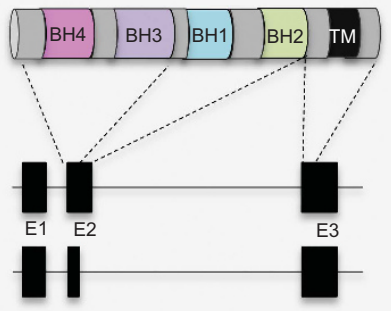

NM138578 $(B C L-X(L))$

NM001191 (BCL-X(S))

d

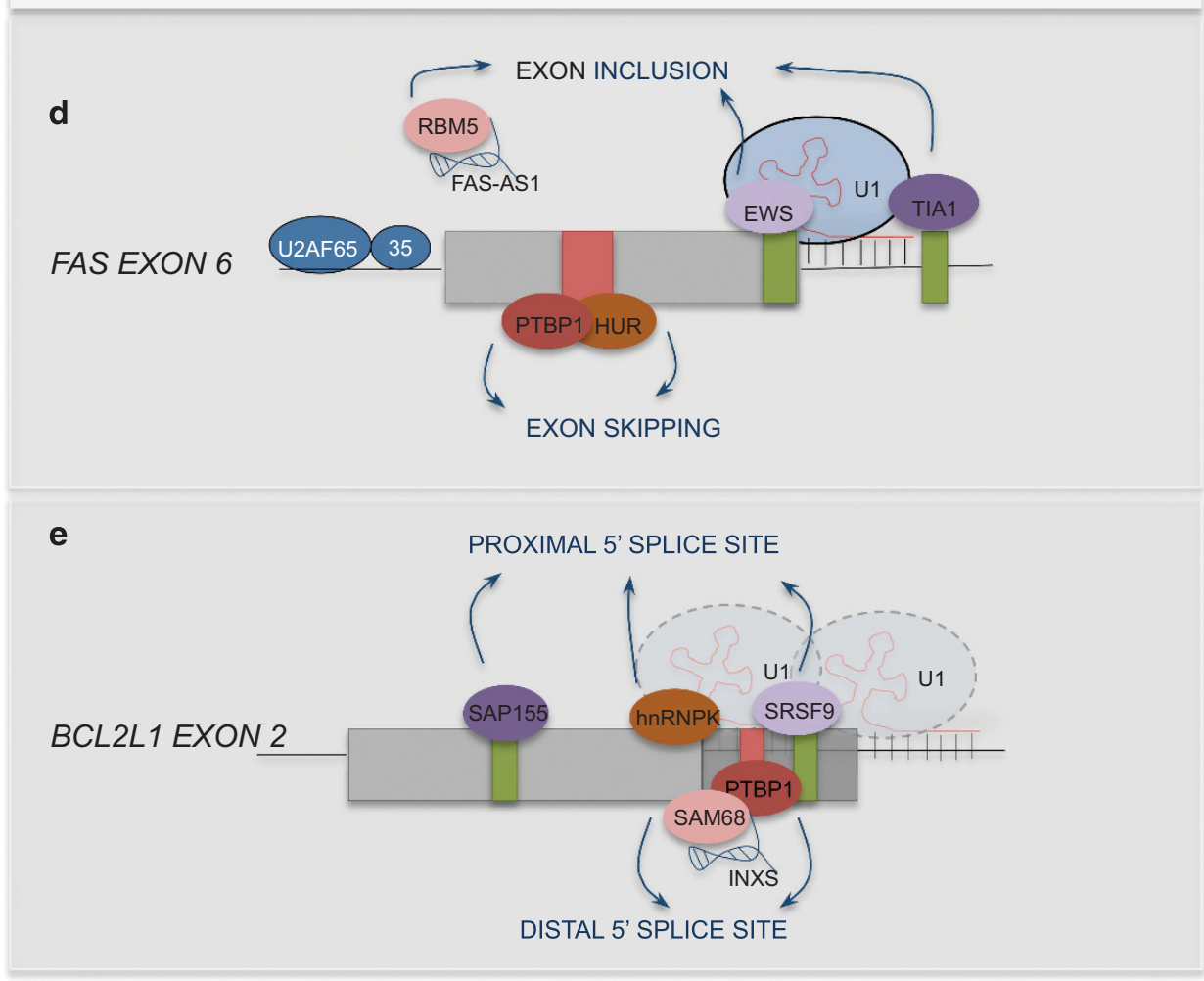

FAS EXON 6

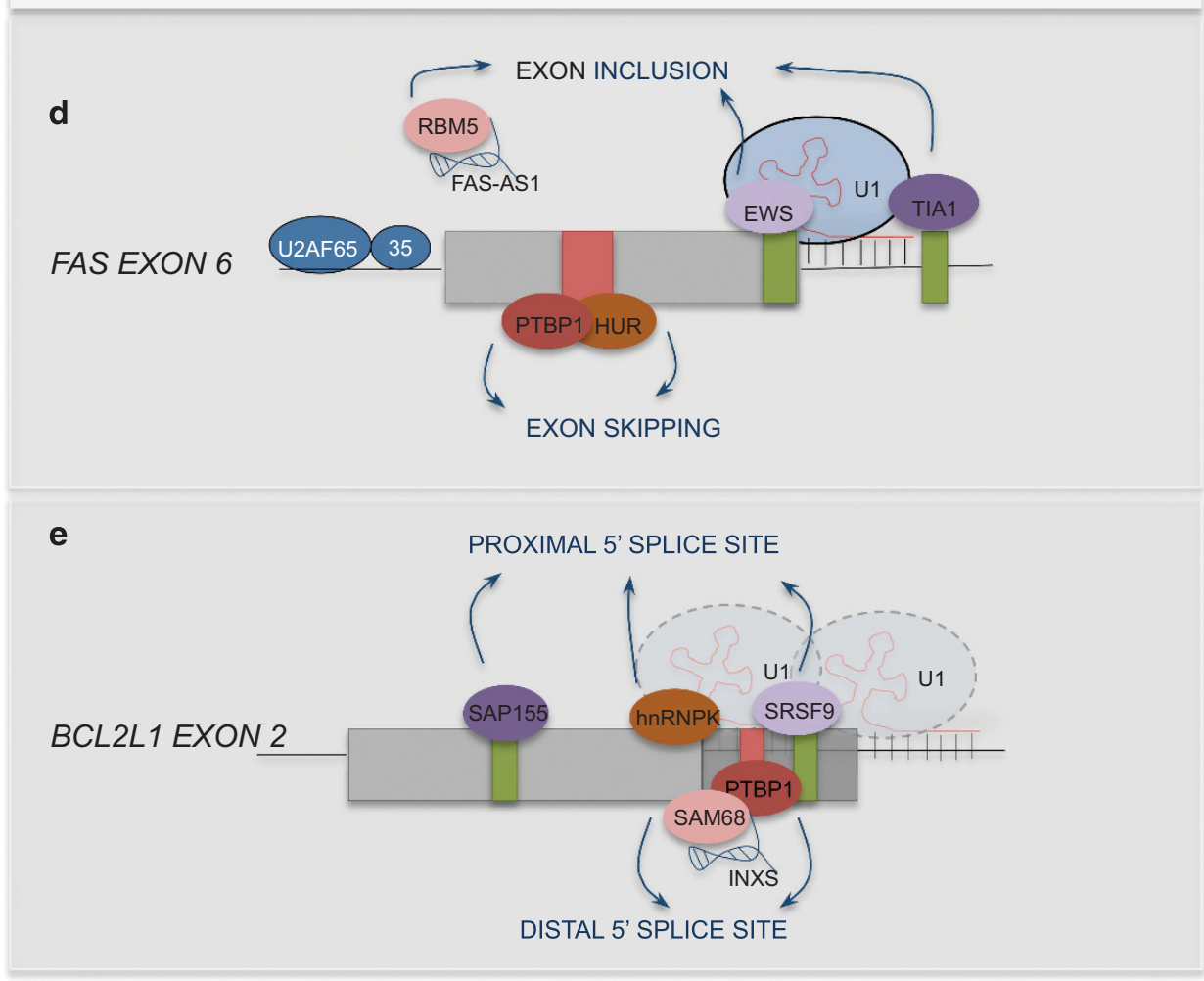


predicted to phosphorylate hnRNP L, suggesting that this mechanism is part of their oncogenic program. HnRNP $U$ competes with $h n R N P L$ for the same sequence, but produces opposite effects on the splicing outcome. ${ }^{38}$ Since AKTdependent phosphorylation of hnRNP $L$ alters this balance and promotes splicing of caspase $9 S,{ }^{37,38}$ targeting it by specific kinase inhibitors might represent an attractive approach for treatment of NSCLC and other cancers. ${ }^{36-38}$

BCL-X. The B-cell lymphoma-2 (BCL-2) protein family contains pro- and anti-apoptotic members. Pro-apoptotic proteins, such as BAX, cause formation of pores in the mitochondrial outer membrane eliciting its permeabilization. ${ }^{1-4}$ Anti-apoptotic $\mathrm{BCL}-2$ proteins protect cells by interacting with and preventing the activities of pro-apoptotic family members. ${ }^{1-4}$

$B C L-X(B C L 2 L 1$ gene) is an essential member of the BCL-2 family. Bcl2/1-deficient mice die around embryonic day 13, show death of hematopoietic cells in the liver, shortened lifespan of immature lymphocytes and extensive apoptosis of neurons in brain. ${ }^{39} B C L 2 L 1$ encodes two main splice variants: ${ }^{13}$ the anti-apoptotic $B C L-X_{L}$ (233 amino acids) and the pro-apoptotic BCL- $X_{S}$, which lacks 63 internal amino acids comprising two $\mathrm{BCL}-2$ family-homology regions $(\mathrm{BH} 1$ and $\mathrm{BH} 2$ ) (Figure 2c). Accordingly, mutations in the $\mathrm{BH} 1$ or $\mathrm{BH} 2$ regions of $B C L-2$ and $B C L-X_{L}$ disrupt their ability to heterodimerize with $B A X$ and to inhibit apoptosis. ${ }^{41}$ Other $B C 2 L 1$ splice variants with pro- $(B C L-X \beta)$ and anti-apoptotic (BCL$\mathrm{X}_{\triangle \mathrm{TM}}, \mathrm{BCL}-\mathrm{X}_{Y}$ ) functions have been described in mouse and human, ${ }^{42-44}$ however the mechanisms underlying their AS regulation are still unknown.

$B C L-X_{L}$ and $X_{S}$ originate from two alternative 5 '-splice sites in exon 2. Selection of the proximal site at the end of the exon yields $B C L-X_{L}$, whereas $B C L-X_{S}$ originates from usage of a distal cryptic site $\sim 200$ bp upstream. ${ }^{13} \mathrm{HnRNP} \mathrm{F,} \mathrm{H},{ }^{45}$ and I

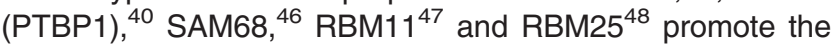
pro-apoptotic BCL-X $\mathrm{S}_{\mathrm{S}}$ variant, whereas SAP155, ${ }^{49} \mathrm{SRSF},{ }^{50}$ hnRNP $\mathrm{K}^{51}$ and SRSF1 ${ }^{46,52}$ enhance splicing of BCL- $\mathrm{X}_{\mathrm{L}}$ (Figure 2e). Site-specific and deletion mutagenesis identified two regions that are important for BCL-X splice site selection. One upstream of the proximal 5'-splice site enforces BCL- $X_{L}$ splicing, while the other region, located immediately downstream of the distal 5 '-splice site, favors BCL-X Sroduction. $^{45}$ $\mathrm{HnRNP} \mathrm{F} / \mathrm{H}$ proteins bind guanosine stretches in this second element and stimulate splicing of $B C L-X_{S}^{45,53}$ Moreover,
PTBP1 binds to a polypyrimidine tract between the two alternative $5^{\prime}$ splice sites, in proximity of the hnRNP $\mathrm{F} / \mathrm{H}$ binding site, displacing SRSF1 from the BCL- $X_{L} 5^{\prime}$ splice site and repressing its selection. ${ }^{40}$

Activation of signaling pathways modulate binding of splicing factors to cis-regulatory elements in the BCL-X premRNA. Ceramide, a regulator of stress and proliferation, affects BCL- $X_{L} 5^{\prime}$ splice site selection by recruiting SAP155 to a purine-rich cis-element in exon $2 .{ }^{49}$ Ceramide also induced extensive dephosphorylation of SR proteins, ${ }^{54}$ thus influencing AS of BCL2L1 and CASP9. ${ }^{55}$ These findings are in line with the observation that ceramide induces cell cycle arrest, differentiation and apoptosis, ${ }^{56}$ and suggest that AS modulation by signaling pathways could be exploited for therapeutic purpose. Another splicing factor regulated by post-translational modifications is SAM68. ${ }^{57}$ When it is upregulated, SAM68 favors splicing of BCL- $X_{S}$ and triggers cell death. Tyrosine phosphorylation by FYN disrupted SAM68-hnRNP A1 interaction and binding to RNA, reverting $B C L-X$ splicing. ${ }^{46}$ Interaction with the transcription factor FBI-1 also decreased SAM68 recruitment to the premRNA and restored splicing of $B C L-X_{L}^{58}$. Thus, modulation of SAM68 phosphorylation and/or protein-protein interactions can finely tune cell survival through AS of antagonistic BCL-X variants.

A genome-wide screening identified the mitotic aurora kinase A (AURKA) as regulator of BCL2L1 splicing. ${ }^{52}$ Mitotic arrest and/or AURKA inhibitors promoted splicing of BCL- $X_{S}$ by increasing the turnover of SRSF1, which normally enhances BCL- $X_{L}$ splicing. ${ }^{52}$ These observations revealed a novel connection between AS regulation and apoptosis in response to activation of a cell cycle checkpoint.

Recruitment of splicing factors to the BCL-X pre-mRNA can be also regulated by IncRNAs. INXS is transcribed from the $B C L 2 L 1$ locus in antisense direction and its expression is lower in cancer cells. ${ }^{59}$ Apoptosis-inducing agents upregulate INXS and favor splicing of BCL-X $\mathrm{X}_{\mathrm{S}}$. INXS interacts directly with SAM68, suggesting that it may function by recruiting it to the BCL-X pre-mRNA. When INXS is absent or expressed at low levels the predominant output of splicing is BCL- $X_{L}$. Intratumor injections of a plasmid encoding this IncRNA, however, increased expression of $\mathrm{BCL}-\mathrm{X}_{\mathrm{S}}$ and reduced tumor burden in a mouse xenograft model. ${ }^{60}$ Hence, downregulation of INXS in cancer might contribute to resistance to apoptosis, and its

Figure 2 Regulation of alternative splicing in apoptotic genes. (a) FAS protein scheme showing the three main domains (upper): signal peptide (SP), transmembrane domain (TM) and death domain (DD). DD is a protein module composed of a bundle of six $\alpha$-helices. The lower panel shows the annotated FAS transcripts. Exons encoding each domain are indicated. NM000043 is the longest mRNA variant. The NM152871 variant 2 (FAS $\triangle \mathrm{Ex6}$ ) lacks an in-frame exon encoding the transmembrane region. The NM152872 variant 3 (FAS $\triangle$ Ex8) lacks a coding segment, which leads to a translation frameshift and a distinct, shorter C-terminus compared with isoform 1. The NR028034 (5), NR028035 (6), NR028033 (4) and NR028036 (7) variants lack, respectively, three (5), two (6 and 4) or one (7) alternative coding exons compared with variant 1 and are candidates for NMD. (b) In the upper panel, the three main domains of the CASP9 protein are depicted: CARD domain and the two catalytic domains (p18 and p10). The lower panel shows the annotated CASP9 transcripts. Exons encoding each protein domain are indicated. The NM001229 variant $(\alpha)$ encodes the longest isoform. The NM032996 variant differs in the 5'-UTR, lacks a portion of the 5'-coding region and yields a shorter N-terminus. The NM001278054 variant $(\beta)$ lacks four alternative in-frame exons in the coding region and encodes the caspase-9 S isoform. (c) BCL-X comprises four BCL-2 homology (BH) domains. The anti-apoptotic BCL- $\mathrm{X}_{\mathrm{L}}$ isoform (NM138578 variant) contains all BH domains and a transmembrane (TM) domain that anchors the protein to cellular membranes, including the mitochondrial outer membrane. The pro-apoptotic BCL-X $\mathrm{X}_{S}$ isoform (NM001191 variant) uses an alternate in-frame 5'-splice site in exon 2, yielding a smaller protein that lacks BH2. (d) Alternative splicing of FAS is controlled by TIA-1, EWS, PTB and HUR, which directly bind the pre-mRNA and either promote or inhibit exon 6 inclusion. The IncRNA FAS-AS1 affects FAS alternative splicing by sequestering RBM5 and preventing its inhibitory effect of FAS exon 6 inclusion. (e) Regulation of BCL2L1 alternative splicing. Enhancer and silencer cis-elements are indicated in either in green or in red. Representative splicing factors (SAP155, hnRNP K, hnRNP F/H, PTBP1 and SRSF9) and IncRNAs (INXS) affecting the recognition of the proximal (upper factors) or distal (lower factors) 5 ' splice site are depicted 
targeted induction could be exploited for the development of a RNA-based therapy.

\section{Alternative Splicing and Cancer Cell Survival}

AS of genes involved in cell survival is often altered in cancer and contributes to the ability of neoplastic cells to withstand hostile environments. ${ }^{9,61-64}$ In most cases, transformed cells opt for mechanisms that promote splice variants with prosurvival activity. This paradigm is exemplified by the regulation of the TP53 gene. ${ }^{65}$ TP53 encodes for a transcription factor (p53) whose upregulation exerts tumor-suppressor function by promoting apoptosis and senescence in response to cellular stresses. ${ }^{65}$ However, TP53 is often mutated in cancer cells, thus relieving this negative feedback and providing them with an opportunity to by-pass checkpoints activated by cellular or genetic alterations. Notably, in the remaining cancer cells where the TP53 gene is still functional, its aberrant splicing often yields loss of function or antagonistic variants that repress this apoptotic response. ${ }^{62,65}$ Another way to keep p53 expression low is through its degradation. The MDM2 ubiquitin ligase that promotes p53 degradation is often upregulated in cancer cells. ${ }^{66}$ More than 70 MDM2 splice variants have been described in cancer cells. ${ }^{66}$ These variants potentially encode proteins with different functions, further expanding the splicing control of TP53 in cancer. Moreover, the homologous MDM4 protein levels are normally kept low by exon 6 skipping and degradation of the transcript by NMD. ${ }^{59}$ However, SRSF3mediated inclusion of this exon in cancer cells yields full-length MDM4 expression and consequent suppression of p53. ${ }^{59}$ Since antisense oligonucleotide (ASO)-mediated skipping of exon 6 reduced tumor burden in mouse models of melanoma and lymphoma, ${ }^{59}$ it is conceivable that regulation of this AS event might represent a therapeutic target of clinical relevance (Figure 3a).

$B C L 2 L 1$ splicing also has a role in human cancer. Expression of BCL- $X_{L}$ correlates with increased chemoresistance of cancer cells ${ }^{67}$ and upregulation of SRSF1 might underlie its preferential splicing. ${ }^{52} \mathrm{BCL}-\mathrm{X}_{\mathrm{L}}$ splicing is enhanced when SRSF1 is phosphorylated by NEK2, ${ }^{68}$ a mitotic kinase frequently overexpressed in cancer. ${ }^{68,69}$ Conversely, SRSF1 activity is counteracted by RBM4, which promotes $\mathrm{BCL}-\mathrm{X}_{\mathrm{S}}$ splicing and apoptosis. RBM4 is downregulated in cancer patients and its expression correlates with better prognosis. ${ }^{70}$ Thus, upregulation of the NEK2-SRSF1 axis and/or RBM4 downregulation might lead to high expression of $B C L-X_{L}$ in cancer. This feature can be exploited therapeutically by switching splicing toward the pro-apoptotic BCL- $X_{S}$ through splice site-specific ASOs $^{67,71}$ (Figure 3a). Delivery of such ASOs by lipid nanoparticles was efficacious to reduce tumor size and metastasis in a mouse model of melanoma, ${ }^{72}$ indicating the potential of this approach.

\section{Alternative Splicing in Chemoresistance}

Loss of checkpoints, dysregulation of cell cycle progression and/or enhanced response to growth factors underlie the unrestrained proliferation of cancer cells. Although chemotherapy represents an effective approach to counteract these features, cancer cells often develop resistance. Thus, elucidation of the molecular mechanisms involved in the acquisition of resistance is strategic to develop more efficacious therapies for human cancer. AS contributes to chemoresistance by enhancing plasticity of gene expression during the adaptive response to stress. ${ }^{64}$ In this section, we report some splicing events and factors that are involved in such response. Other examples have been recently illustrated in extensive reviews on this topic. ${ }^{73,74}$

Genotoxic stress imposed by chemotherapy or irradiation induces changes in AS that affect cell survival. ${ }^{75-78}$ This scenario suggests that cancer cells may develop resistance by modulating the expression or activity of splicing factors required for cell survival and/or by selection of cells that express the repertoire of splicing factors conferring prosurvival features. For instance, although most drugs increased splicing of BCL- $X_{S}$ in non-neoplastic cells, only a subset of cancer cells showed the same regulation. ${ }^{75}$ Thus, identification of splicing factors involved in splicing of oncogenic variants may pave the path to new therapeutic approaches.

SRSF1 upregulation causes neoplastic transformation, at least in part, through splicing of pro-oncogenic variants involved in proliferation and survival. ${ }^{72}$ SRSF1 was upregulated upon short-term treatment of pancreatic adenocarcinoma (PDAC) cells with gemcitabine. SRSF1 promoted splicing of MNK2b, which in turn caused constitutive activation of the MAPK pathway and phosphorylation of the translation initiation factor elF4E, thus enhancing cell survival. ${ }^{79}$ These observations linked SRSF1 expression to the adaptive response to genotoxic stress (Figure 4).

AS contributes also to selection of PDAC cells that are stably resistant to drugs. Cells isolated after chronic exposure to gemcitabine displayed an altered splicing pattern of the pyruvate kinase (PKM) gene. ${ }^{80}$ PKM encodes for two splice variants generated by usage of mutually exclusive exons 9 (PKM1) or exon 10 (PKM2). PKM2 is expressed during embryogenesis and promotes glycolytic metabolism. However, its expression is restored in cancer cells. ${ }^{81}$ Gemcitabineresistant clones showed higher PKM2/PKM1 ratio with respect to parental cell lines, and reversion of PKM splicing by an ASO-mediated approach rescued drug sensitivity. ${ }^{80}$ Among the factors involved in the regulation of $P K M$ splicing, ${ }^{82}$ PTBP1 was upregulated in drug-resistant clones and favored PKM2 splicing by binding intron 8 and repressing exon 9 inclusion. Knockdown of PTBP1 expression reverted the PKM2/PKM1 ratio and rescued sensitivity to gemcitabine, ${ }^{80}$ suggesting that targeting the PTBP1/PKM axis may counteract acquisition of chemoresistance in PDAC cells (Figure 4).

HnRNP $\mathrm{H}$ contributes to chemoresistance by altering splicing of the Thymidine phosphorylase (TP) gene. TP is an enzyme required for the conversion of capecitibine to 5-fluorouracil. HnRNP $\mathrm{H}$ binds intron 1 and exon 6 sequences in TP pre-mRNA, causing intron retention and degradation by NMD. ${ }^{83}$ Accordingly, leukemia cells expressing high levels of hnRNP $\mathrm{H}$ showed lower expression of TP protein and increased chemoresistance with respect to parental cells. ${ }^{83}$ Hence, modulation of the expression of a splicing factor during chemotherapy may favor survival by altering the metabolic route required for the effect of the drug.

SAM68 is upregulated in prostate cancer $(\mathrm{PCa})^{84}$ and other human cancers, ${ }^{57,85}$ where it contributes to cell proliferation 


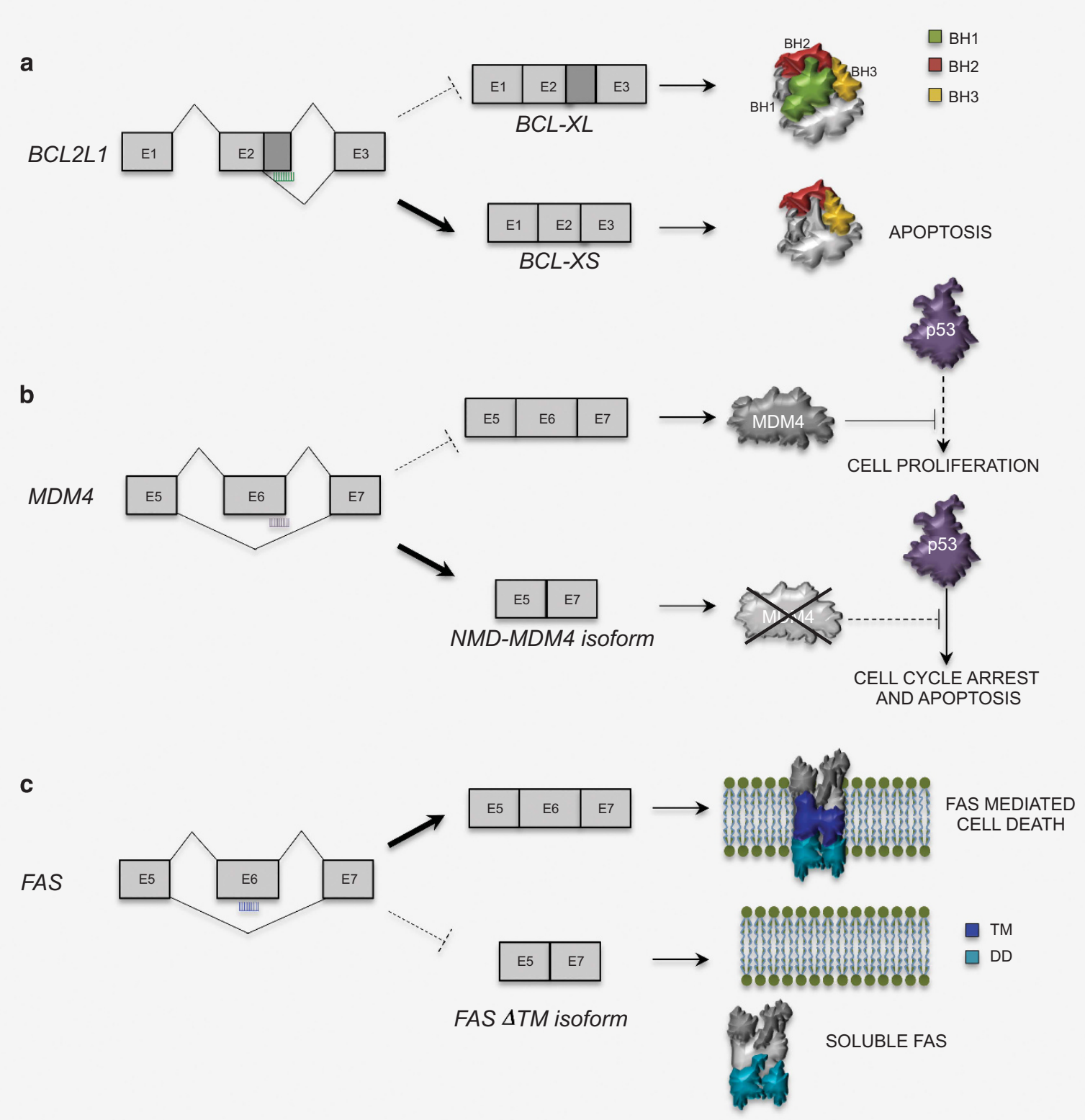

Figure 3 Cancer therapies based on antisense oligonucleotide-mediated splicing modulation. (a) Treatment of cancer cells with an ASO masking the proximal $5{ }^{\prime}$ splice site effectively switches BCL-X splicing and induces apoptosis. (b) MDM4 protein is highly expressed in embryonic tissues and in cancers as a result of enhanced exon 6 inclusion, driven mainly by SRSF3. ASO-promoting skipping of exon 6 is a suitable approach to inhibit p53 degradation by MDM4 in cancer cells. (c) Example of the hypothetical application of ASO therapy to FAS. An ASO masking the PTBP1-binding site in FAS exon 6 could be rescue FAS exon 6 inclusion, thus enhancing FAS-mediated cell death of cancer cells

and survival. SAM68 modulates AS of cancer-relevant genes, as $C D 44,{ }^{86} B C L 2 L 1,{ }^{46} C C N D 1^{87}$ and $A R,{ }^{88}$ generally favouring oncogenic splice variants. Thus, its upregulation might represent a general feature of transformed cells, which confers an advantage by setting in motion an oncogenic splicing program. For instance, upon genotoxic stress, SAM68 clustered to foci of active transcription and promoted oncogenic CD44 variants. ${ }^{89}$

In some cases, the splicing factors responsible for AS events involved in chemoresistance are still unknown. Mutation of BAX in cancers characterized by microsatellites instability generally confers resistance to cell death. ${ }^{90}$
However, a unique combination of microsatellite deletion in exon 3 with exon 2 skipping generates the $\operatorname{BAX} \Delta 2$ isoform in some microsatellite unstable tumors, which is a potent deathinducer that sensitizes cells to chemotherapy. ${ }^{91,92}$ Furthermore, genotoxic stress induces inclusion of the alternative exon $6 \mathrm{~A}$ of the DHX9 helicase in Ewing Sarcoma cells. DHX9 interacts with the oncogenic EWS-FLI1 transcription factor and enhances its recruitment on target gene promoters. ${ }^{78}$ Exon $6 \mathrm{~A}$ contains a PTC and leads to NMD, thus reducing DHX9 protein expression and sensitizing cells to apoptosis. ${ }^{78}$ These findings indicate that an NMD-linked splicing event 


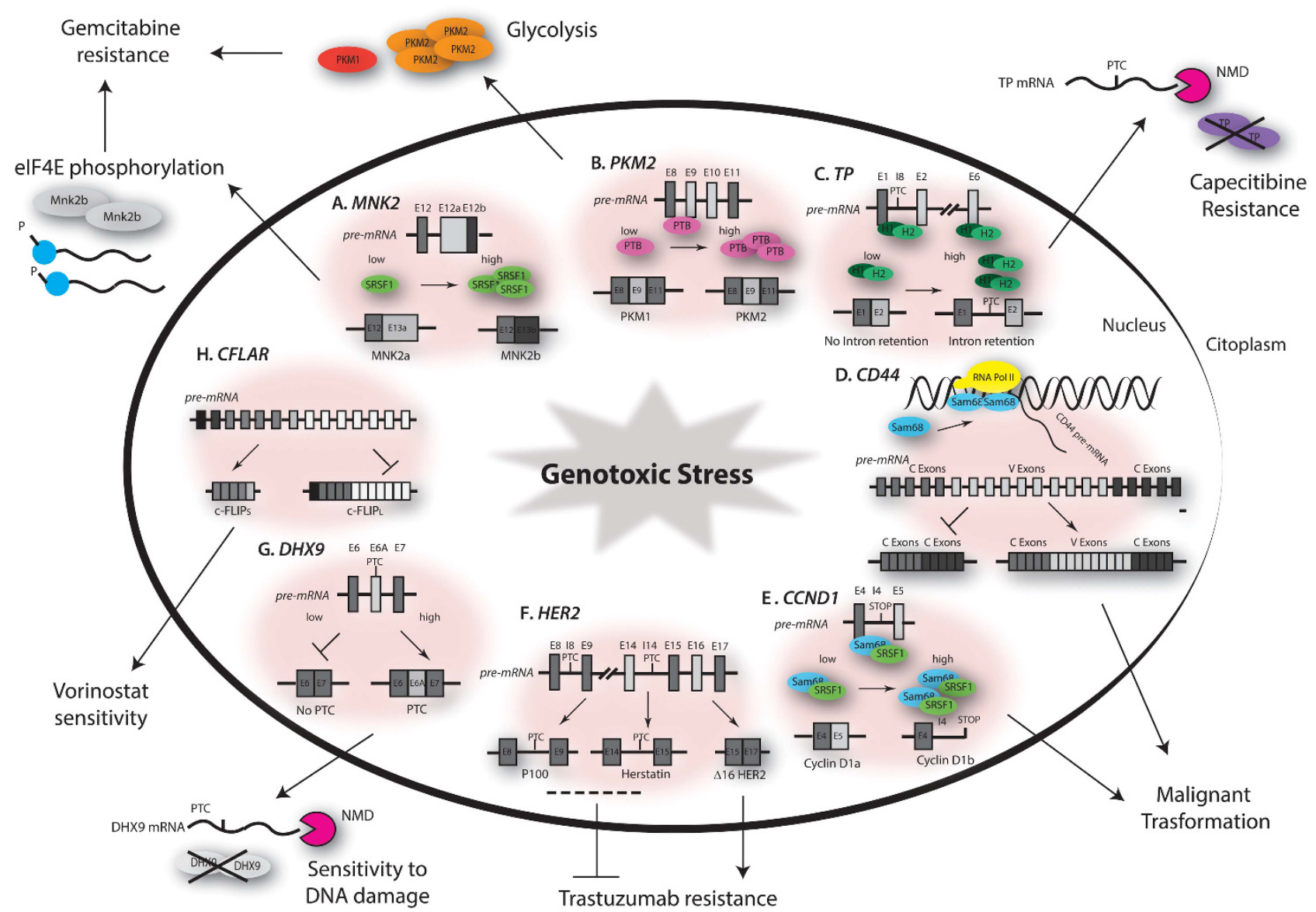

Figure 4 Alternative splicing and chemoresistance. Schematic representation of representative splicing events involved in genotoxic stress response. Gemcitabine resistance in pancreatic cancer is favored by short-term upregulation of SRSF1, MNK2b splicing (A) and elF4E phosphorylation, or by long-term upregulation of PTBP1 and splicing of the pro-oncogenic PKM2 isoform (B). In AML, hnRNPs H1/H2 cause NMD-linked splicing of TP (C), leading to resistance to capecitibine. In prostate cancer, mitoxantrone causes a relocalization of SAM68 in active transcription sites (D), and leads to the inclusions of CD44 variable exons which confers pro-oncogenic features. In prostate cancer, malignant transformation correlates also with the upregulation of SAM68 and SRSF1, which promote the pro-oncogenic Cyclin D1b variant (E). In breast cancer, alternative splicing of HER2 confers different sensitivity to trastuzumab (F). Genotoxic stress causes the inclusion of exon 6 in DHX9 transcript in Ewing sarcoma cells (G), leading to NMD of DHX9 mRNA and sensitizing cells to apoptosis. In AML, expression of the shorter isoform of CFLAR gene, c-FLIPs, correlates with sensitivity to Vorinostat (H)

exerts a direct impact on EWS-FLI1 oncogenic activity in sarcomas (Figure 4).

The splicing signature of cancer cells can be used to predict response to chemotherapy. In Acute Myeloid Leukemia (AML), patients with high expression of the long splice variant of C-FLIP (C-FLIP $\mathrm{L}$ ) displayed lower overall survival. ${ }^{93} \mathrm{C}-\mathrm{FLIP}$ inhibits cleavage of caspase 8 and negatively regulates apoptosis. Treatment with the drug Vorinostat downregulated C-FLIP $P_{L}$ and enhanced cell death induced by combined treatment with TNF-related apoptosis-inducing ligand (TRAIL). ${ }^{93}$ These findings suggest that modulation of a single splicing event could represent a therapeutic approach for AML.

Another example of splice variant correlating with poor prognosis in patients is cyclin D1b. It originates from CCND1 intron 4 retention and transcription termination upstream of exon $5 .{ }^{94}$ Cyclin D1b is retained in the nucleus and more stable than the canonical variant. ${ }^{94}$ It was associated with tumor progression and poor outcome in $\mathrm{PCa},{ }^{95}$ while cyclin D1b expression in mice induced cellular transformation and tumor growth, confirming its oncogenic potential. ${ }^{96}$ Since
SAM6 $8^{87}$ and $\mathrm{SRSF} 1^{97}$ promote this splice variant in $\mathrm{PCa}$ cells and are upregulated in patients, ${ }^{84,97}$ it is likely that dysregulation of CCND1 AS is part of their oncogenic program in the prostate (Figure 4).

HER-2, a member of the epidermal growth factor receptor (EGFR) family, is frequently upregulated in breast cancers. The monoclonal anti-HER-2 antibody (trastuzumab) represents the elective therapy for these patients. ${ }^{98}$ Three HER-2 splice variants differently influence response to chemotherapy and cell survival in breast cancer. $\triangle 16 \mathrm{HER} 2$ originates from exon 16 skipping and is associated with malignant transformation and trastuzumab resistance. ${ }^{99}$ The other splice variants, P100 and Herstatin, derive from retention of intron 14 and intron 8, respectively, and formation of a PTC. Both encode truncated proteins that interact with HER2 and impair its activity, ${ }^{100,101}$ conferring a disadvantage for cancer progression (Figure 4). Thus, characterization of HER-2 splice variants in breast cancer patients could contribute to prognosis and be predictive of the efficacy of chemotherapy. 


\section{Emerging Implication of Alternative Splicing in the Regulation of Autophagy}

Autophagy is an evolutionarily conserved mechanism employed by cells to adapt to hostile conditions. ${ }^{102}$ Autophagy maintains cellular homeostasis in the absence of essential nutrients and its regulation is sensitive to changes in cell metabolism. ${ }^{103}$ Under starvation or other stressful conditions, specific signal transduction pathways trigger the formation of membrane vesicles (autophagosomes) that encapsulate molecules, macromolecules or organelles. Autophagosomes fuse with lysosomes and the entrapped cellular components are degraded to fuel ATP synthesis and support metabolic routes under adverse conditions.

Regulation of autophagy involves many proteins that act in coordinated fashion in response to stimuli. It mainly relies on rapid post-translational mechanisms that directly influence the activity, stability or localization of autophagic proteins. ${ }^{102,103}$ However, modulation of gene expression also contributes to fine-tune this process, as starvation activates a transcriptional program that coordinates the autophagic response with lysosomal biogenesis. ${ }^{104}$

Changes in transcription are often linked to changes in $A S^{76}$ and recent studies have unveiled the contribution of $A S$ to autophagy regulation. BECN1 is a key component of the multiprotein complex that promotes nucleation of autophagosome precursors. ${ }^{102,103}$ AS converts BECN1 from an inducer of nonselective macroautophagy to a regulator of mitochondriaselective autophagy. ${ }^{105}$ BECN1s, a shorter splice variant originating from skipping of exons 10 and 11 , selectively localizes in the outer membrane of mitochondria and contributes to mitophagy in response to starvation or mitochondrial membrane depolarization. ${ }^{105} \mathrm{New}$ splice variants were also identified in members of the autophagy-related gene 8 (ATG8) family (LC3B, GABARAP and GABARAPL1). ${ }^{106}$ They encode proteins that are not integrated in the autophagosomes, suggesting that they could limit autophagy. In the case of LC3B, the LC3B-a variant originates from AS of intron 3, leading to a single amino acid deletion (Arg68). ${ }^{106}$ This study highlights the power of AS to generate variants differing for single amino acids but displaying opposite activities.

AS can influence the autophagic response of cancer cells. DU145 PCa cells lack the canonical ATG5, ${ }^{107}$ an essential protein for autophagy, ${ }^{102}$ but express two alternative mRNAs that lack either exon 6 or exon 3 and 6 , leading to premature termination of translation. ${ }^{108}$ As a consequence, autophagy was not induced in DU145 cells by treatment with a chemotherapeutic agent that normally induces autophagy. Likewise, oncogenic U2AF35 mutants were shown to promote transformation by aberrant processing of ATG7 pre-mRNA, leading to an autophagy defect. ${ }^{108}$

Although very preliminary, these observations suggest that autophagy, like apoptosis, is likely modulated by AS through production of variants displaying different activities. Given the emerging role of autophagy in human diseases, ${ }^{102,103}$ a better understanding of the impact of AS on the autophagic response will highlight new paths for the development of tools that modulate this process.

\section{Conclusions and Perspectives}

The complexity of the human genome is exemplified by the flexibility with which each gene is regulated through AS. ${ }^{12}$ Nevertheless, this flexibility is also a risk factor, as many human diseases are linked to defective splicing. Thus, comprehension of the molecular basis of its regulation is believed to offer therapeutic perspective. Some approaches in this sense are already being developed. In Spinal Muscular Atrophy (SMA), rescue of SMN2 exon 7 splicing represents a valuable therapy. An ASO interfering with binding of splicing repressors corrected SMN2 splicing and rescued viability in mouse models. ${ }^{109}$ This ASO is in clinical trial for SMA (ISIS 396443; www.clinicaltrials.gov), a disease for which no cure is available, ${ }^{110}$ indicating that aberrant splicing is a 'druggable' defect. In principle, redirection of splicing outcome by ASOs could be applied to other genes implicated in disease (Figure 3). Genes involved in cell survival represent good candidates for human cancers. In some cases, such as for the 'unhealthy' splice variants of BCL2L $1,{ }^{71} P K M^{80}$ and MDM4, ${ }^{59}$ preclinical evidence of ASOs efficacy has been provided and this paves the ground for clinical oriented studies. Improvement in ASO chemistry and administration protocols has recently ameliorated their efficacy in patients. An ASO directed against SMAD7 elicited positive clinical responses, and in some cases disease remission, in patients affected by Crohn's disease. ${ }^{111}$ Elucidation of the AS events associated with cell survival and autophagy in human diseases will offer new therapeutic targets, in addition to representing diagnostic and prognostic tools. With these premises, development of splicing-directed therapies have the potential to become standard approaches to counteract cancer development and/or the adaptive response of cancer cells to chemotherapy.

\section{Conflict of Interest}

The authors declare no conflict of interest.

Acknowledgements. This work was supported by grants from the Associazione Italiana Ricerca sul Cancro (AIRC) IG14581 (to CS) and IG17278 (to MPP), from the Association for International Cancer Research (AICR-UK) 12-0150 (to CS) and 14-0333 (to MPP), from the University of Rome 'Foro Italico' RIC052013 (to MPP), from Telethon GGP 14095 (to CS), from Ministry of Health 'Ricerca Corrente' to Fondazione Santa Lucia.

1. Yuan J, Kroemer G. Alternative cell death mechanisms in development and beyond. Genes Dev 2010; 24: 2592-2602.

2. Green DR, Galluzzi L, Kroemer G. Mitochondria and the autophagy-inflammation-cell death axis in organismal aging. Science 2011; 333: 1109-1112.

3. Green DR, Galluzzi L, Kroemer G. Cell biology. Metabolic control of cell death. Science 2014; 345: 1250256

4. Green DR. Apoptotic pathways: the roads to ruin. Cell 1998: 94: 695-698.

5. Oppenheim RW. Cell death during development of the nervous system. Annu Rev Neurosci 1991; 14: 453-501.

6. Creedon DJ, Johnson EM Jr, Lawrence JC Jr. Mitogen-activated protein kinaseindependent pathways mediate the effects of nerve growth factor and cAMP on neuronal survival. J Biol Chem 1996; 271: 20713-20718.

7. Purves D, Snider WD, Voyvodic JT. Trophic regulation of nerve cell morphology and innervation in the autonomic nervous system. Nature 1988; 336: 123-128.

8. Matsuda F, Inoue N, Manabe N, Ohkura S. Follicular growth and atresia in mammalian ovaries: regulation by survival and death of granulosa cells. J Reprod Dev2012; 58: 44-50.

9. Schwerk C, Schulze-Osthoff K. Regulation of apoptosis by alternative pre-mRNA splicing Mol Cell 2005; 19: 1-13.

10. Wahl MC, Will CL, Lührmann R. The spliceosome: design principles of a dynamic RNP machine. Cell 2009; 136: 701-718. 
11. Black DL. Mechanisms of alternative pre-messenger RNA splicing. Annu Rev Biochem 2003; 72: 291-336.

12. Fu XD, Ares M Jr. Context-dependent control of alternative splicing by RNA-binding proteins. Nat Rev Genet 2014; 15: 689-701.

13. Boise LH, Gonzalez-Garcia M, Postema CE, Ding L, Lindsten T, Turka LA et al. bcl-x, a bcl2-related gene that functions as a dominant regulator of apoptotic cell death. Cell 1993; 74 597-608.

14. Walke DW, Morgan JI. A comparison of the expression and properties of Apaf-1 and Apaf1 L. Brain Res 2000; 886: 73-81.

15. Wang L, Miura M, Bergeron L, Zhu H, Yuan J. Ich-1, an Ice/ced-3-related gene, encodes both positive and negative regulators of programmed cell death. Cell 1994; 78: 739-750.

16. Liu G, Nozell S, Xiao H, Chen X. DeltaNp73beta is active in transactivation and growth suppression. Mol Cell Biol 2004; 24: 487-501.

17. Turnquist C, Horikawa I, Foran E, Major EO, Vojtesek B, Lane DP et al. p53 isoforms regulate astrocyte-mediated neuroprotection and neurodegeneration. Cell Death Differ 2016: 1515-1528

18. Krammer PH. CD95's deadly mission in the immune system. Nature 2000; 407: 789-795.

19. Bidere N, Su HC, Lenardo MJ. Genetic disorders of programmed cell death in the immune system. Annu Rev Immunol 2006; 24: 321-352.

20. Cascino I, Papoff G, De Maria R, Testi R, Ruberti G. Fas/Apo-1/CD95 receptor lacking the intracytoplasmic signaling domain protects tumor cells from Fas-mediated apoptosis. J Immunol 1996; 156: 13-17.

21. Förch P, Puig O, Kedersha N, Martínez C, Granneman S, Séraphin B et al. The apoptosispromoting factor TIA-1 is a regulator of alternative pre-mRNA splicing. Mol Cell 2000; 6 : 1089-1098.

22. Paronetto MP, Bernardis I, Volpe E, Bechara E, Sebestyén E, Eyras E et al. Regulation of FAS exon definition and apoptosis by the Ewing sarcoma protein. Cell Rep 2014; 7 : 1211-1226.

23. Förch $P$, Puig $O$, Martínez $C$, Séraphin $B$, Valcárcel J. The splicing regulator TIA-1 interacts with U1-C to promote U1 snRNP recruitment to $5^{\prime}$ splice sites. EMBO J 2002; 21 $6882-6892$.

24. Knoop LL, Baker SJ. The splicing factor U1C represses EWS/FLI-mediated transactivation. J Biol Chem 2000; 275: 24865-24871.

25. Izquierdo JM, Majós N, Bonnal S, Martínez C, Castelo R, Guigó R et al. Regulation of Fas alternative splicing by antagonistic effects of TIA-1 and PTB on exon definition. Mol Cell 2005; 19: 475-484.

26. Izquierdo JM, Valcárcel J. Fas-activated serine/threonine kinase (FAST K) synergizes with TIA-1/TIAR proteins to regulate Fas alternative splicing. J Biol Chem 2007; 282: $1539-1543$.

27. Izquierdo JM. Hu antigen R (HuR) functions as an alternative pre-mRNA splicing regulator of Fas apoptosis-promoting receptor on exon definition. J Biol Chem 2008; 283 19077-19084.

28. Bonnal S, Martínez C, Förch P, Bachi A, Wilm M, Valcárcel J. RBM5/Luca-15/H37 regulates Fas alternative splice site pairing after exon definition. Mol Cell 2008; 32: 81-95.

29. Sehgal L, Mathur R, Braun FK, Wise JF, Berkova Z, Neelapu S et al. FAS-antisense 1 IncRNA and production of soluble versus membrane Fas in B-cell lymphoma. Leukemia 2014; 28: 2376-2387.

30. Tejedor JR, Papasaikas $P$, Valcárcel J. Genome-wide identification of Fas/CD95 alternative splicing regulators reveals links with iron homeostasis. Mol Cell 2015; 57 : 23-38.

31. Kumar S. ICE-like proteases in apoptosis. Trends Biochem Sci 1995; 20: 198-202.

32. Thornberry NA, Lazebnik Y. Caspases: enemies within. Science 1998; 281: 1312-1316.

33. Rodriguez J, Lazebnik Y. Caspase- 9 and APAF-1 form an active holoenzyme. Genes Dev 1999: 13: 3179-3184.

34. Kuida K, Haydar TF, Kuan C-Y, Gu Y, Taya C, Karasuyama H et al. Reduced apoptosis and cytochrome c-mediated caspase activation in mice lacking caspase-9. Cell 94: 325-3371998.

35. Seol DW, Billiar TR. A caspase-9 variant missing the catalytic site is an endogenous inhibitor of apoptosis. J Biol Chem 1999; 274: 2072-2076.

36. Shultz JC, Goehe RW, Murudkar CS, Wijesinghe DS, Mayton EK, Massiello A et al. SRSF1 regulates the alternative splicing of caspase-9 via a novel intronic splicing enhancer affecting the chemotherapeutic sensitivity of non-small cell lung cancer cells. Mol Cancer Res 2011; 9: 889-900.

37. Goehe RW, Shultz JC, Murudkar C, Usanovic S, Lamour NF, Massey DH et al. hnRNP L regulates the tumorigenic capacity of lung cancer xenografts in mice via caspase-9 premRNA processing. J Clin Invest 2010; 120: 3923-3939.

38. Vu NT, Park MA, Shultz JC, Goehe RW, Hoeferlin LA, Shultz MD et al. hnRNP U enhances caspase- 9 splicing and is modulated by AKT-dependent phosphorylation of hnRNP L. J Biol Chem 2013; 288: 8575-8584

39. Motoyama N, Wang F, Roth KA, Sawa H, Nakayama KI, Nakayama K et al. Massive cell death of immature hematopoietic cells and neurons in bcl-x-deficient mice. Science 1995; 267: 1506-1510.

40. Bielli P, Bordi M, Biasio VD, Sette C. Regulation of BCL-X splicing reveals a role for the polypyrimidine tract binding protein (PTBP1/hnRNP I) in alternative $5^{\prime}$ splice site selection. Nucleic Acids Res 2014; 42: 12070-12081.

41. Yin XM, Oltvai ZN, Korsmeyer SJ. BH1 and BH2 domains of $\mathrm{Bcl}-2$ are required for inhibition of apoptosis and heterodimerization with Bax. Nature 1994; 369: 321-323.
42. Fang W, Rivard JJ, Mueller DL, Behrens TW. Cloning and molecular characterization of mouse bcl-x in B and T lymphocytes. J Immunol 1994; 153: 4388-4398.

43. Shiraiwa N, Inohara N, Okada S, Yuzaki M, Shoji S, Ohta S. An additional form of rat Bcl-x, Bcl-xbeta, generated by an unspliced RNA, promotes apoptosis in promyeloid cells. J Biol Chem 1996; 271: 13258-13265.

44. Ye Q, Press B, Kissler S, Yang XF, Lu L, Bassing $\mathrm{CH}$ et al. T cell costimulation through CD28 depends on induction of the Bcl-xgamma isoform: analysis of Bcl-xgammadeficient mice. J Exp Med 2002; 196: 87-95.

45. Garneau D, Revil T, Fisette JF, Chabot B. Heterogeneous nuclear ribonucleoprotein F/H proteins modulate the alternative splicing of the apoptotic mediator Bcl-x. J Biol Chem 2005; 280: 22641-22650.

46. Paronetto MP, Achsel T, Massiello A, Chalfant CE, Sette C. The RNA-binding protein Sam68 modulates the alternative splicing of Bcl-x. J Cell Biol 2007; 176: 929-939.

47. Pedrotti S, Busà R, Compagnucci $C$, Sette $C$. The RNA recognition motif protein RBM11 is a novel tissue-specific splicing regulator. Nucleic Acids Res 2012; 40: 1021-1032.

48. Zhou A, Ou AC, Cho A, Benz EJ Jr, Huang SC. Novel splicing factor RBM25 modulates Bclx Pre-mRNA 5' splice site selection. Mol Cell Biol 2008; 28: 5924-5936.

49. Massiello A, Roesser JR, Chalfant CE. SAP155 Binds to ceramide-responsive RNA ciselement 1 and regulates the alternative 5 ' splice site selection of $\mathrm{Bcl}-\mathrm{x}$ pre-mRNA. FASEB J 2006; 20: 1680-1682.

50. Cloutier P, Toutant J, Shkreta L, Goekjian S, Revil T, Chabot B. Antagonistic effects of the SRp30c protein and cryptic $5^{\prime}$ splice sites on the alternative splicing of the apoptotic regulator Bcl-x. J Biol Chem 2008; 283: 21315-21324.

51. Revil T, Pelletier J, Toutant J, Cloutier A, Chabot B. Heterogeneous nuclear ribonucleoprotein $\mathrm{K}$ represses the production of pro-apoptotic Bcl-xS splice isoform. J Biol Chem 2009; 284: 21458-21467.

52. Moore MJ, Wang Q, Kennedy CJ, Silver PA. An alternative splicing network links cell-cycle control to apoptosis. Cell 2010; 142: 625-636.

53. Dominguez C, Fisette JF, Chabot B, Allain FH. Structural basis of G-tract recognition and encaging by hnRNP F quasi-RRMs. Nat Struct Mol Biol 2010; 17: 853-861.

54. Chalfant CE, Ogretmen B, Galadari S, Kroesen BJ, Pettus BJ, Hannun YA. FAS activation induces dephosphorylation of SR proteins; dependence on the de novo generation of ceramide and activation of protein phosphatase 1. J Biol Chem 2001; 276: 44848-44855.

55. Chalfant CE, Rathman K, Pinkerman RL, Wood RE, Obeid LM, Ogretmen B et al. De novo ceramide regulates the alternative splicing of caspase 9 and $\mathrm{Bcl}-\mathrm{x}$ in $\mathrm{A} 549$ lung adenocarcinoma cells. Dependence on protein phosphatase-1. J Biol Chem 2002; 277 : 12587-12595

56. Obeid LM, Linardic CM, Karolak LA, Hannun YA. Programmed cell death induced by ceramide. Science 1993; 259: 1769-1771.

57. Frisone P, Pradella D, Di Matteo A, Belloni E, Ghigna C, Paronetto MP. SAM68: Signal transduction and RNA metabolism in human cancer. Biomed Res Int 2015; 2015: 528954.

58. Bielli $P$, Busà R, Di Stasi SM, Munoz MJ, Botti F, Kornblihtt AR et al. The transcription factor FBI-1 inhibits SAM68-mediated BCL-X alternative splicing and apoptosis. EMBO Rep 2014; 15: 419-427.

59. Dewaele M, Tabaglio T, Willekens K, Bezzi M, Teo SX, Low DH et al. Antisense oligonucleotide-mediated MDM4 exon 6 skipping impairs tumor growth. J Clin Invest 2015; 126: 68-84.

60. DeOcesano-Pereira C, Amaral MS, Parreira KS, Ayupe AC, Jacysyn JF, AmaranteMendes GP et al. Long non-coding RNA INXS is a critical mediator of BCL-XS induced apoptosis. Nucleic Acids Res 2014; 42: 8343-8355.

61. Zhang J, Manley JL. Misregulation of pre-mRNA alternative splicing in cancer. Cancer Discov 2013; 3: 1228-1237.

62. Chen J, Weiss WA. Alternative splicing in cancer: implications for biology and therapy. Oncogene 2015; 34: 1-14.

63. Sveen A, Kilpinen S, Ruusulehto A, Lothe RA, Skotheim RI. Aberrant RNA splicing in cancer; expression changes and driver mutations of splicing factor genes. Oncogene 2015; 35: 2413-2427.

64. Pagliarini V, Naro C, Sette C. Splicing regulation: a molecular device to enhance cancer cell adaptation. Biomed Res Int 20152015: 543067.

65. Levine AJ, Oren M. The first 30 years of p53: growing ever more complex. Nat Rev Cancer 2009; 9: 749-758.

66. Rosso M, Okoro DE, Bargonetti J. Splice variants of MDM2 in oncogenesis. Subcell Biochem 2014; 85: 247-261.

67. Mercatante DR, Mohler JL, Kole R. Cellular response to an antisense-mediated shift of $\mathrm{Bcl}$ $x$ pre-mRNA splicing and antineoplastic agents. J Biol Chem 2002; 277: 49374-49382.

68. Naro C, Barbagallo F, Chieffi P, Bourgeois CF, Paronetto MP, Sette C. The centrosomal kinase NEK2 is a novel splicing factor kinase involved in cell survival. Nucleic Acids Res 2014; 42: 3218-3227.

69. Zhou W, Yang Y, Xia J, Wang H, Salama ME, Xiong W et al. NEK2 induces drug resistance mainly through activation of efflux drug pumps and is associated with poor prognosis in myeloma and other cancers. Cancer Cell 2013; 23: 48-62.

70. Wang Y, Chen D, Qian H, Tsai YS, Shao S, Liu Q et al. The splicing factor RBM4 controls apoptosis, proliferation, and migration to suppress tumor progression. Cancer Cell 2014; 26: 374-389.

71. Bauman JA, Li SD, Yang A, Huang L, Kole R. Anti-tumor activity of splice-switching oligonucleotides. Nucleic Acids Res 2010; 38: 8348-8356. 
72. Karni R, de Stanchina E, Lowe SW, Sinha R, Mu D, Krainer AR. The gene encoding the splicing factor SF2/ASF is a proto-oncogene. Nat Struct Mol Biol 2007; 14: 185-193.

73. Eblen ST. Regulation of chemoresistance via alternative messenger RNA splicing Biochem Pharmacol 2012; 83: 1063-1072.

74. Shkreta $L$, Chabot B. The RNA splicing response to DNA damage. Biomolecules 2015; 5 2935-2977.

75. Shkreta L, Froehlich U, Paquet ER, Toutant J, Elela SA, Chabot B. Anticancer drugs affect the alternative splicing of $\mathrm{Bcl}-\mathrm{x}$ and other human apoptotic genes. Mol Cancer Ther 2008; 7 : 1398-1409.

76. Muñoz MJ, Pérez Santangelo MS, Paronetto MP, de la Mata M, Pelisch F, Boireau S et al. DNA damage regulates alternative splicing through inhibition of RNA polymerase elongation. Cell 2009; 137: 708-720.

77. Dutertre M, Sanchez G, De Cian MC, Barbier J, Dardenne E, Gratadou L et al Cotranscriptional exon skipping in the genotoxic stress response. Nat Struct Mol Biol 2010; 17: $1358-1366$.

78. Fidaleo M, Svetoni F, Volpe E, Miñana B, Caporossi D, Paronetto MP. Genotoxic stress inhibits Ewing sarcoma cell growth by modulating alternative pre-mRNA processing of the RNA helicase DHX9. Oncotarget 2015; 6: 31740-31757.

79. Adesso L, Calabretta S, Barbagallo F, Capurso G, Pilozzi E, Geremia R et al. Gemcitabine triggers a pro-survival response in pancreatic cancer cells through activation of the MNK2/ elF4E pathway. Oncogene 2013; 32: 2848-2857.

80. Calabretta S, Bielli P, Passacantilli I, Pilozzi E, Fendrich V, Capurso G et al. Modulation of PKM alternative splicing by PTBP1 promotes gemcitabine resistance in pancreatic cancer cells. Oncogene 2016; 35: 2031-2039.

81. Christofk HR, Vander Heiden MG, Harris MH, Ramanathan A, Gerszten RE, Wei R et al. The M2 splice isoform of pyruvate kinase is important for cancer metabolism and tumour growth. Nature 2008; 452: 230-233.

82. David CJ, Chen M, Assanah M, Canoll P, Manley JL. HnRNP proteins controlled by c-Myc deregulate pyruvate kinase mRNA splicing in cancer. Nature 2010; 463: 364-368.

83. Stark M, Bram EE, Akerman M, Mandel-Guttreund Y, Assaraf YG. Heterogeneous nuclear ribonucleoprotein $\mathrm{H} 1 / \mathrm{H} 2$ dependent unsplicing of thymidinephosphorylase results in anticancer drug resistance. J Biol Chem 2011; 286: 3741-3754.

84. Busà R, Paronetto MP, Farini D, Pierantozzi E, Botti F, Angelini DF et al. The RNA-binding protein Sam68 contributes to proliferation and survival of human prostate cancer cells. Oncogene 2007; 26: 4372-4382.

85. Bielli $P$, Busà $R$, Paronetto MP, Sette $C$. The RNA-binding protein Sam68 is a multifunctional player in human cancer. Endocr Relat Cancer 2011; 18: R91-R102.

86. Matter $\mathrm{N}$, Herrlich $\mathrm{P}$, König $\mathrm{H}$. Signal-dependent regulation of splicing via phosphorylation of Sam68. Nature 2002; 420: 691-695.

87. Paronetto MP, Cappellari M, Busà R, Pedrotti S, Vitali R, Comstock $C$ et al. Alternative splicing of the cyclin D1 proto-oncogene is regulated by the RNA-binding protein Sam68. Cancer Res 2010; 70: 229-239.

88. Stockley J, Markert E, Zhou Y, Robson CN, Elliott DJ, Lindberg J et al. The RNA-binding protein Sam68 regulates expression and transcription function of the androgen receptor splice variant AR-V7. Sci Rep 2015; 5: 13426.

89. Busà R, Geremia R, Sette C. Genotoxic stress causes the accumulation of the splicing regulator Sam68 in nuclear foci of transcriptionally active chromatin. Nucleic Acids Res 2010; 38: 3005-3018.

90. Rampino N, Yamamoto H, lonov Y, Li Y, Sawai $\mathrm{H}$, Reed JC et al. Somatic frameshift mutations in the BAX gene in colon cancers of the microsatellite mutator phenotype. Science 1997; 275: 967-969.

91. Haferkamp B, Zhang H, Lin Y, Yeap X, Bunce A, Sharpe J et al. BaxDelta2 is a novel bax isoform unique to microsatellite unstable tumors. J Biol Chem 2012; 287: 34722-34729.
92. Zhang $H$, Lin $Y$, Mañas $A$, Zhao $Y$, Denning MF, Ma $L$ et al. Bax $\Delta 2$ promotes apoptosis through caspase-8 activation in microsatellite unstable colon cancer. Mol. Cancer Res 2014; 12: 1225-1232.

93. McLornan D, Hay J, McLaughlin K, Holohan C, Burnett AK, Hills RK et al. Prognostic and therapeutic relevance of C-FLIP in acute myeloid leukaemia. Br J Haematol 2013; 160 : 188-198.

94. Knudsen KE. The cyclin D1b splice variant: an old oncogene learns new tricks. Cell Div 2006; 1: 15.

95. Comstock CE, Augello MA, Benito RP, Karch J, Tran TH, Utama FE et al. Cyclin D1 splice variants: polymorphism, risk, and isoform-specific regulation in prostate cancer. Clin Cancer Res 2009; 15: 5338-5349.

96. Augello MA, Berman-Booty LD, Carr R 3rd, Yoshida A, Dean JL, Schiewer MJ et al. Consequence of the tumor-associated conversion to cyclin D1b. EMBO Mol Med 2015; 7 628-647.

97. Olshavsky NA, Comstock CE, Schiewer MJ, Augello MA, Hyslop T, Sette C et al. Identification of ASF/SF2 as a critical, allele-specific effector of the cyclin D1b oncogene Cancer Res 2010; 70: 3975-3984.

98. Arteaga CL, Sliwkowski MX, Osborne CK, Perez EA, Puglisi F, Gianni L. Treatment of HER2-positive breast cancer: current status and future perspectives. Nat Rev Clin Oncol 2012; 9: 16-32.

99. Mitra D, Brumlik MJ, Okamgba SU, Zhu Y, Duplessis TT, Parvani JG et al. An oncogenic isoform of HER2 associated with locally disseminated breast cancer and trastuzumab resistance. Mol Cancer Ther 2009; 8: 2152-2162.

100. Scott GK, Robles R, Park JW, Montgomery PA, Daniel J, Holmes WE et al. A truncated intracellular HER2/neu receptor produced by alternative RNA processing affects growth of human carcinoma cells. Mol Cell Biol 1993; 13: 2247-2257.

101. Doherty JK, Bond C, Jardim A, Adelman JP, Clinton GM. The HER-2/neu receptor tyrosine kinase gene encodes a secreted autoinhibitor. Proc Nat Acad Sci USA 1999; 96 10869-10874.

102. Mizushima N, Komatsu M. Autophagy: renovation of cells and tissues. Cell 2011; 147 728-741.

103. Galluzzi L, Pietrocola F, Levine B, Kroemer G. Metabolic control of autophagy. Cell 2014 159: 1263-1276.

104. Settembre C, Fraldi A, Medina DL, Ballabio A. Signals from the lysosome: a control centre for cellular clearance and energy metabolism. Nat Rev Mol Cell Biol 2013; 14: 283-296.

105. Cheng B, Xu A, Qiao M, Wu Q, Wang W, Mei $Y$ et al. BECN1s, a short splice variant of BECN1, functions in mitophagy. Autophagy 2015; 11: 2048-2056.

106. Liu C, Ma H, Wu J, Huang Q, Liu JO, Yu L. Arginine68 is an essential residue for the C-terminal cleavage of human Atg8 family proteins. BMC Cell Biol 2013; 14: 27.

107. Ouyang DY, Xu LH, He XH, Zhang YT, Zeng LH, Cai JY et al. Autophagy is differentially induced in prostate cancer LNCaP, DU145 and PC-3 cells via distinct splicing profiles of ATG5. Autophagy 2013; 9: 20-32.

108. Park SM, Ou J, Chamberlain L, Simone TM, Yang H, Virbasius CM et al. U2AF35(S34F) promotes transformation by directing aberrant ATG7 pre-mRNA 3' end Formation. Mol Cell 2016; 62: 479-490.

109. Hua Y, Sahashi K, Rigo F, Hung G, Horev G, Bennett CF et al. Peripheral SMN restoration is essential for long-term rescue of a severe spinal muscular atrophy mouse model. Nature 2011; 478: 123-126.

110. Rigo F, Hua Y, Krainer AR, Bennett CF. Antisense-based therapy for the treatment of spinal muscular atrophy. J Cell Biol 2012; 199: 21-25.

111. Monteleone G, Neurath MF, Ardizzone S, Di Sabatino A, Fantini MC, Castiglione F et al. Mongersen, an oral SMAD7 antisense oligonucleotide, and Crohn's disease. N Engl J Med 2015; 372: 1104-1113.

Supplementary Information accompanies this paper on Cell Death and Differentiation website (http://www.nature.com/cdd) 